\title{
Geoethics: a perspective from Australia
}

\author{
Ian B. Lambert
}

Secretary General, 34th International Geological Congress, Geoscience Australia, Canberra, Australia

\author{
Article history \\ Received January 9, 2012; accepted January 12, 2012. \\ Subject classification: \\ Geoethics, Mining, Sustainability.
}

\begin{abstract}
This short article reflects my experience over many years in provision of the Geoethics symposium at Geoitalia 2011. I was pleased to be invited to provide a brief address at this meeting because it gave me the opportunity to promote the 34th International Geological Congress (IGC) that will to be held in Brisbane, Australia, on August 5-10, 2012, and which will have a strong geoethics symposium. My succinct remarks reflect my experience over many years in provision of technical information and advice in support of Australian government decisions and policies on mining, energy and groundwater - all of which have core geoscientific elements. Further, they reflect the situation in a new world country with a strong economy dominated by mining, which differs in many ways from the countries where the field of geoethics has been nurtured and grown. They also outline a dilemma relating to mining in a developing country.
\end{abstract}

\section{Introduction}

This short article is based on the introductory remarks I made in the Geoethics symposium at Geoitalia 2011. I was pleased to be invited to provide a brief address at this meeting because it gave me the opportunity to promote the 34 th International Geological Congress (IGC) that will to be held - in Brisbane, Australia, on 5-10 August 5-10, 2012 and which is towill have a strong geoethics symposium.

However, I was also apprehensive, because I had had very limited exposure to "geoethics" until 2010. When considering the scope of the scientific program for the IGC, it became obvious that there were some very active researchers and practitioners of geoethics in parts of Europe, and Russia, and in some developing countries. Previously, I was more familiar with terms such as "best practice" and "a social licence to operate", which I submit encompass the essence of geoethics.

This article reflects my experience in provision of technical information and advice in support of Australian government decisions and policies on mining, energy and groundwater, - all of which have core geoscientific elements. Further, it reflects the situation in a new world democracy with a healthy economy that is dominated by mining. As the flattest, most arid, deeply weathered and least-populated of the inhabited continents, Australia differs in many ways from the countries where the field of geoethics has been nurtured and grown, and from others where its practice is particularly important.

After outlining some of the factors used in Australia to balance economic with environmental and social benefits, it this article considers a dilemma relating to mining in a neighbouring developing country, and makes provides some concluding remarks.

\section{The Australian situation}

In Australia, the main industries which that have potential for significant environmental and social impacts include mining, manufacturing, chemicals and agriculture. The last few decades have seen a progressively increasing focus on environmental and social responsibilities. The framework for this is provided by the federal 'Environment and Biodiversity Protection Act', and complementary state and territory legislation. There are also guidelines for good practices for many activities, that have often been developed by governments with constructive industry and community inputs, to increase the probability that they will work in practice.

Professional societies accredit geoscience professionals and develop and disseminate codes of ethics. Many industries and individual companies have also established codes for ethical behaviour and sustainability policies. Achieving a social licence to operate is a widely accepted principle.

Reporting is required for authorised and accidental releases into the environment, and monitoring is undertaken to give early warning of any emerging problems. It is common that governments and industry co-regulate activities, and this generally works well, given the effective checks and balances that are part of the regulatory system. Particularly in the case of mining, rehabilitation funds or bonds are commonly required during operations to cover costs of remedial works after closure.

The legislative framework and broadly transparent 
processes are important in reaching decisions on major projects which that have to balance the various interests and benefits. No system is perfect, but where things are not working out as planned, review processes and public pressure lead to improvements, or closure in extreme cases. The ultimate responsibility to perform satisfactorily is with the companies, and failure to do so can result in heavy fines and even imprisonment of responsible managers.

\section{An ethical dilemma}

In contrast with to Australia's stable setting, the island nations to the northeast, north and northwest are characterised by high rainfall and relief, high seismicity, landslides and volcanic activity, which reflecting their near near-equatorial latitudes and associations with active plate margins. Such geological settings are highly prospective, particularly for world-class copper and gold deposits.

Mining activities in these environments can lead to ethical dilemmas. I will illustrate this for a major multinational company mining a large $\mathrm{Cu}-\mathrm{Au}$ deposit in a developing country, the government of which is part owner of the mine. At the outset, a dam was built to contain tailings on the mine lease. Given the extreme conditions in the region, it was not surprising that this dam soon collapsed. Ever since, tailings have been washing down the river system with government approval. In places, tailings have deposited in overbank areas, fishing has been affected, and some communities have had to be re-located.

This attracted a lot of attention from international non-governmental organisations (NGOs), which have been very vocal in trying to shut the mine, using electronic and other media to disseminate their fears of major permanent environmental destruction. At this stage, I suspect that many of you will be agreeing with the NGOs and thinking of what action you would take to help achieve mine closure.

Where is the ethical dilemma? Government Ministers ministers from the developing country have angrily denounced the pressure to close the mining operations. They have questioned the rights of foreigners to protest against the mine, stating that these people are not speaking in the best interests of the developing country, which has received schools, hospitals, jobs and income from the mine. They pointed out that scientists who have studied the river system have concluded that the main impacts will greatly diminish as it is all flushed out by floods after the mining ceases, and that no significant environmental changes have been detected in the marine zones beyond the deposits at the river mouth.

I will leave it to geoethical practitioners to consider where the moral high ground is in such a situation, and to ponder other situations where communities are benefitting from better services and lifestyles in the short short- to to-medium term through activities which that need to be conducted ethically to sustain communities in the longer term.

\section{Concluding remarks}

Many activities that are undertaken to meet societal needs, or simply for financial gain, as well as natural disasters, can have can impact on environments and communities. It is harder to hide and ignore damaging activities and events now than in the past, because the internet and social media are provideing powerful means for exposing these and for exerting pressure on those causing the problems. Governments have primary responsibility for putting into place an effective framework of measures to minimise minimize the impacts within their jurisdictions.

In most developed countries, there are formal and informal approaches designed to keep impacts within reason. These vary from highly prescriptive - where a fixed set of practices or particular technologies are specified - to outcomes outcomes-based regulation based on underpinning principles. These approaches are generally effective, although there will always be a the need for vigilance, to avoid distortions and cutting corners for financial gain.

In those developing and centrally planned countries where bad practices and corruption are widespread, sound foundations for ethical behaviour depends primarily on the appropriate legislation, good governance and a balance of assistance and penalties.

Geoethicists have particularly important roles to play in promoting the responsible behaviours and practices that are required for sustainable development. A measure of their success will be increasing levels of employment in governments and companies, to help achieve these ends.

Corresponding author: Ian B. Lambert, email: ian.lambert@ga.gov.au.

(C) 2012 by the Istituto Nazionale di Geofisica e Vulcanologia. All rights reserved. 